\title{
Antimicrobial Effect of Different Types of Honey on Selected ATCC Bacterial Strains
}

\author{
Aseel Aljaghwani' ${ }^{1}$, Khaled S. Allemailem ', Lujain F. Aljaghwani' ${ }^{2}$, Faris Alrumaihi' ${ }^{1}$, Rejo Jacob Joseph ${ }^{3}$, Amjad \\ Ali Khan ${ }^{3}$, Mohammad aljaghwani ${ }^{4}$, Arshad H. Rahmani ${ }^{1}$, Ahmad Almatroudi ${ }^{1}$,*
}

Aseel Aljaghwani', Khaled

S. Allemailem ${ }^{1}$, Lujain F.

Aljaghwani ${ }^{2}$, Faris Alrumaihi ${ }^{1}$,

Rejo Jacob Joseph ${ }^{3}$, Amjad Ali

Khan $^{3}$, Mohammad aljaghwani ${ }^{4}$,

Arshad H. Rahmani' ${ }^{1}$, Ahmad

Almatroudi ${ }^{1, *}$

'Department of Medical Laboratories, College of Applied Medical Sciences, Qassim University, Buraydah, SAUDI ARABIA. ${ }^{2}$ Department of Obstetrics and Gynecology, Maternity and Children Hospital, Buraydah, SAUDI ARABIA.

${ }^{3}$ Department of Basic Health Sciences, College of Applied Medical Sciences, Qassim University, Buraydah, SAUDI ARABIA.

${ }^{4}$ Department of Cardiovascular and Catheter Laboratory, Prince Sultan Center for Cardiac Medicine and Surgery, Buraydah, SAUDI ARABIA.

\section{Correspondence}

\section{Ahmad Almatroud}

Department of Medical Laboratories, College of Applied Medical Sciences, Qassim University, Buraydah, SAUDI ARABIA

E-mail: aamtrody@qu.edu.sa

\section{History}

- Submission Date: 05-11-2020;

- Review completed: 28-11-2020;

- Accepted Date: 08-12-2020.

DOI : 10.5530/pj.2021.13.31

Article Available online http://www.phcogj.com/v13/i1

Copyright

(C) 2021 Phcogj.Com. This is an openaccess article distributed under the terms of the Creative Commons Attribution 4.0 International license.

\section{ABSTRACT}

Honey is a complex sweet highly viscous liquid and is composed of various ingredients such as sugar, proteins, minerals, and polyphenolic compounds. Honey is used in traditional medicine systems for centuries because of its ability to inhibit the pathogenesis of various diseases through modulating various biological activities. In this study, antimicrobial potential of different types of honey was tested against selected pathogenic bacterial strains through agar well diffusion method. Four types of honey were used in the present investigation, and the potential antimicrobial activities of these varieties were further compared with that of antibiotics commonly used against targeted microbial strains. Among all of the four tested honey, three types were classified as blossom honey, being Talha (Acacia sp) honey (TH), Zahoor (mixed flower) honey ( $\mathrm{ZH}$ ), and Manuka (Leptospermum based honey) honey (MH). Both gram positive and gram negative bacterial species were used for this investigation. The pathogenic gram-positive bacterial strains included Staphylococcus aureus ATCC 29213, Enterococcus faecalis ATCC 29212 and methicillin-resistant Staphylococcus (MRSA) ATCC 43300. Three gram negative bacteria like Escherichia coli ATCC 25922, Klebsiella pneumonia ATCC 700603 and Pseudomonas aeruginosa ATCC 27853 were also used to confirm the antimicrobial activities. As reflected from our study, we found that three varieties of honey including $\mathrm{TH}, \mathrm{ZH}$, and $\mathrm{MH}$ (with different UMF $+20,+16,+5$ ) displayed a broad spectrum antibacterial activity against all tested microbial strains. However, all strains showed a high frequency of resistance to BF honey. Gram-positive $(\mathrm{G}+$ ) bacteria were found to be more sensitive to all tested honey types except (BF) as indicated by significantly higher zone of inhibition (ZOI) values than those of gram-negative (G-) bacteria. As a conclusion, this study suggests that antimicrobial potential of honey types might be helpful in order to treat the pathogenic microorganisms threatening the public health and changing antibiotics into last-resort drugs.

Key Words: Talha honey, Zahoor honey and Manuka honey, Staphylococcus aureus, Enterococcus faecalis.

\section{INTRODUCTION}

Honey is a complex sweet liquid with greater viscosity made by bees. It is graded by color, with clear, golden amber and darker honey. The flavor of each type of honey varies, depending on the types of flowers. ${ }^{1}$ Honey is a complex food substance, comprised of approximately 200 deferent substances, including sugar, water, proteins, vitamins, minerals, polyphenolic compounds and plant derivatives. ${ }^{2,3}$ Honey can be classified as honeydew and blossom. Honeydew honey is produced by collection of living plant, aphid and insect secretions whereas blossom honey is produced by collection of flower nectar and characterized by pollen content. Blossom honey can be subdivided into uni-floral, which is from one flower species, or multiflora where multiple sources of flower species. The composition of active compounds present within plant nectar can vary, depending on geographical location and climate conditions. ${ }^{4,5}$ Honey has antimicrobial and antioxidant properties in which the first observations of the antimicrobial activity of honey described in 1892. The honey has then been observed to have a broad spectrum of activity. It can also inhibit both Gram positive and Gram negative organisms including Escherichia coli, Pseudomonas aeruginosa, Klebsiella pneuomniae, Staphylococcus aureus, Bacillus subtilis and Listeria monocytogens and their multidrug-resistant counterparts. ${ }^{6,7}$ Observing the broad spectrum of activity showed by honey, mostly against MDR and many types of antibiotics have led to investigate honey-antibiotic synergy with some promising effects. ${ }^{8}$ Honey contain different types of substances contributing to eradicate and kill microbial pathogen and these substances are classified into two categories, being direct inhibitory factors affecting the cellular mechanism such as polyphonic component, hydrogen peroxide, methylglyoxal (MGO) and bee-defensin1, and indirect inhibitory factors which have a wider ranging effect on the bacterial cell such as high osmatic pressure, high sugar content and low $\mathrm{pH}^{9}{ }^{9}$ A recent study showed that Manuka +20 , Manuka +16 and Manuka +10 have strong antibacterial activities against both sensitive and resistant $P$. aeruginosa strains in addition to $P$. aeruginosa ATCC 27853 which served as control. A previous study showed that Manuka honey of lower UMF grade demonstrated equal to significantly increased antimicrobial activity compared to higher
Cite this article: Aljaghwani A, Allemailem KS, Aljaghwani LF, Alrumaihi F, Joseph RJ, Khan AA, et al. Antimicrobial Effect of Different Types of Honey on Selected ATCC Bacterial Strains Pharmacog J. 2021;13(1): 217-25 
UMF grade honey for all tested organisms. The study included 128 bacterial organisms that were selected for antimicrobial susceptibility testing, being coagulase-positive and coagulase-negative Staphylococci, enteric gram-negative bacilli and P. aeruginosa. MRSA and some MDR bacteria were included. ${ }^{10,11}$

A very recent study demonstrated that Talha honey had higher antimicrobial activity than Sidr honey which showed strong antibacterial activities against pathogenic gram-positive bacteria including Bacillus cereus and $S$. aureus, and gram-negative bacteria including $E$ coli and Salmonella enteritidis. ${ }^{12}$ A previous study showed that black forest honey had highest antibacterial activity against $P$. aeruginosa ATCC 27853 and least with E. coli ATCC $25922 .{ }^{13}$

This study aimed to evaluate the antimicrobial potential of different types of honey including Talha (Acacia sp.) honey, Zahoor honey (mixed flower) and Manuka honey (Leptospermum based honey) with different UMF $(+20,+16,+5)$ against selected pathogenic bacterial strains. Their potential antimicrobial activities were also compared with that of antibiotics commonly used against targeted microbial strains.

\section{MATERIALS AND METHODS}

\section{Honey samples}

Four types of honey were used. Three types were classified as blossom honey, being Talha (Acacia sp) honey, Zahoor honey (mixed flower) and Manuka honey (Leptospermum based honey) with different UMF $(+20,+16,+5)$. These honeys are usually made from the nectar of the flowers. One type is classified as honeydew, being Black Forest honey which is produced from trees. It can also be produced from larger species of grasses and plants (Table 1).

All types of honey were collected from apiaries of selected regions among countries, such as Saudi Arabia, Germany and New Zealand for in vitro analysis purposes in order to determine their antimicrobial activities against selected pathogenic bacterial strains.

\section{Microbial strains}

The pathogenic bacterial strains included three gram-positive bacteria, being Staphylococcus aureus ATCC 29213, Enterococcus faecalis ATCC 29212 and methicillin-resistant Staphylococcus (MRSA) ATCC 43300. Three gram-negative bacteria, being Escherichia coli ATCC 25922, Klebsiella pneumonia ATCC 700603 and Pseudomonas aeruginosa ATCC 27853 were also included. All strains were obtained from the bacterial cultures stocks and supplied by the Department of microbiology, College of Applied medical sciences, Qassim University.

\section{Assessment of antibacterial activity}

Agar well diffusion method was used to determine the antimicrobial potential of different types of honey. Muller-Hinton agar and Muller-

Table 1: Honey samples collected from different regions.

\begin{tabular}{|c|c|c|}
\hline Honey type & Botanical origin & Honey source \\
\hline Talh honey (TH) & Acacia gerrardii Benth & Saudi Arabia \\
\hline Zahoor honey (ZH) & (mixed flower) & Saudi Arabia \\
\hline Black forest honey (B.F) & $\begin{array}{l}\text { Honeydew honey is } \\
\text { made from the aphids } \\
\text { secretion on the leaves } \\
\text { of trees }\end{array}$ & Germany \\
\hline Manuka +20 & $\begin{array}{c}\text { (Leptospermum based } \\
\text { honey) }\end{array}$ & New Zealand \\
\hline Manuka +16 & $\begin{array}{c}\text { (Leptospermum based } \\
\text { honey) }\end{array}$ & New Zealand \\
\hline Manuka +5 & $\begin{array}{c}\text { (Leptospermum based } \\
\text { honey) }\end{array}$ & New Zealand \\
\hline
\end{tabular}

Hinton agar with $5 \%$ sheep blood were used. Bacterial suspension from pure isolates of each microbe were prepared in Muller-Hinton broth under aseptic condition. The density of each suspension was adjusted with $0.5 \%$ McFarland standard. The tested organisms were then inoculated into MHA using lawn culture technique.

After inoculation; 3 wells were made in agar plate using a sterile cork borer (10 mm diameter). The lower portion of the wells was sealed with melted MHA agar. The wells were completely filled with $330 \mu$ of the honey. The agar plates were then incubated at $37^{\circ} \mathrm{C}$ for overnight. The zone of inhibition was checked and the diameter of zone of inhibition was measured using measuring ruler. Vancomycin 30, imipenem 10, amikacin 30 were used as positive controls. All experiments were performed as triplicate.

\section{Statistical analysis}

The mean antimicrobial activity of all tested honey types against each tested bacterial strain was measured. The data were analyzed using analysis of Microsoft Excel Software and analyzed using IPE INFO 7. Statistical means were compared for significant differences at $p \leq 0.05$.

\section{RESULTS}

Different types of honey including Talha (TH), Zahoor $(\mathrm{ZH})$, and Manuka (MH) with different UMF $+20,+16,+5$ and Black Forest (BF) were tested for in vitro antimicrobial activities and evaluated against selected pathogenic bacterial strains. Three Gram-positive bacteria, being S. aureus ATCC 29213, E. faecalis ATCC 29212 and MRSA ATCC 43300 and three Gram-negative bacteria including E.coli ATCC 25922, K. pneumonia ATCC 700603 and P. aeruginosa ATCC 27853 were used. Natural forms of honey were used for testing their potential antimicrobial activity. The data revealed that $\mathrm{TH},(\mathrm{ZH}), \mathrm{MH}$ with different $\mathrm{UMF}+20,+16,+5$ honey types have significant antimicrobial potentialities against microbial strains. BF honey has no significant antimicrobial potentialities as microbial strains were found to be resistant to this type of honey. The microbial strains were significantly inhibited as measured in terms of their zone of inhibition (ZOI), and a large ZOI reflected a high sensitivity of tested microbial strains. Grampositive $(\mathrm{G}+)$ bacteria were found to be more sensitive to all tested honey types except $(\mathrm{BF})$ with significantly higher $\mathrm{ZOI}$ values than those of Gram-positive (G-) bacteria as stated in Table 2.

S. aureus showed the greatest inhibition zone with MA $20+(24.6 \mathrm{~mm})$, followed by MRSA showing $23 \mathrm{~mm}$ ZOI. The least inhibition zone was recorded for MRSA, E. faecalis and $P$. aeruginosa with BF showing only $10 \mathrm{~mm}$ ZOI (Table 2).

\section{Manuka honey}

MA 20+ was found to be the most effective type of MH probably due to the concentration of MGO. It was effective against the most tested strain such as MRSA, S. aureus and E. faecalis showing $25 \mathrm{~mm} \mathrm{ZOI,}$ whereas the least ZOI was $P$. aeruginosa showing $14 \mathrm{~mm}$ ZOI (Figure 1). On the other hand, MA +16 showed slightly smaller ZOI, being MRSA as $21 \mathrm{~mm}$, S. aureus showing $21.6 \mathrm{~mm}$ and E. faecalis showed $19.3 \mathrm{~mm}$ ZOI. P. aeruginosa had $12 \mathrm{~mm}$ ZOI (Figure 2).

$\mathrm{MA}+5$ was found to be the least effective Manuka honey type. It was very effective against MRSA, being $22 \mathrm{~mm}$ followed by $S$. aureus with $20.6 \mathrm{~mm}$ ZOI. ZOI of P. aeruginosa was the least showing only $13.6 \mathrm{~mm}$ (Figure 3).

The inhibition zones due to TH were found to be quite similar to the $\mathrm{MH}$ results compared to others honey types. MRSA was the most effected bacteria showing $20.6 \mathrm{~mm}$ ZOI followed by S. aureus showing 20.3 $\mathrm{mm}$ ZOI. TH was also found to be the most effective honey type on $P$. aeruginosa which showed $15.6 \mathrm{~mm}$ ZOI. The least ZOI was determined in K. pneumonia, being only $14.3 \mathrm{~mm}$ (Figure 4 ). 
Table 2: ZOI for all tested strain. The values were found to be statistically significant $(p<0.05)$.

\begin{tabular}{|c|c|c|c|c|c|c|}
\hline \multicolumn{7}{|c|}{ Different types of honey } \\
\hline Microbial strain & MA20+ & MA16+ & MA5+ & T.H & Z.H & B.F \\
\hline $\mathrm{G}+$ Bacteria & \multicolumn{6}{|c|}{ Zone of inhibition in $\mathrm{mm}$ (ZOI $\mathrm{mm})$} \\
\hline S. aureus & 24.6 & 21.6 & 20.6 & 20.3 & 15 & 12.3 \\
\hline E. faecalis (B) & 25 & 19.3 & 15 & 19 & 15.6 & 10 \\
\hline$P$. aeruginosa & 14 & 12 & 13.6 & 15.6 & 14.3 & 10 \\
\hline K. pneumoniae & 19.6 & 20.3 & 16.3 & 14.3 & 12.6 & 12.3 \\
\hline E. coli & 22.3 & 21 & 17.6 & 15.6 & 13.6 & 12 \\
\hline
\end{tabular}

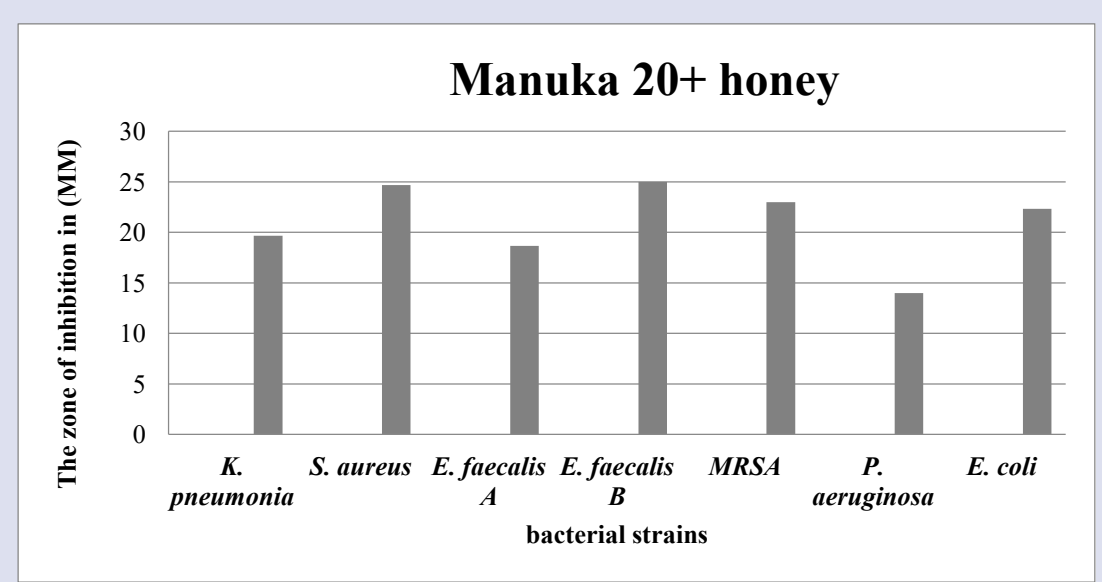

Figure 1: Antimicrobial activities of Manuka 20+ honey against tested bacterial strains The largest three of ZOI E. faecalis (B), S. aureus and MRSA. Were the least one P. aeruginosa.

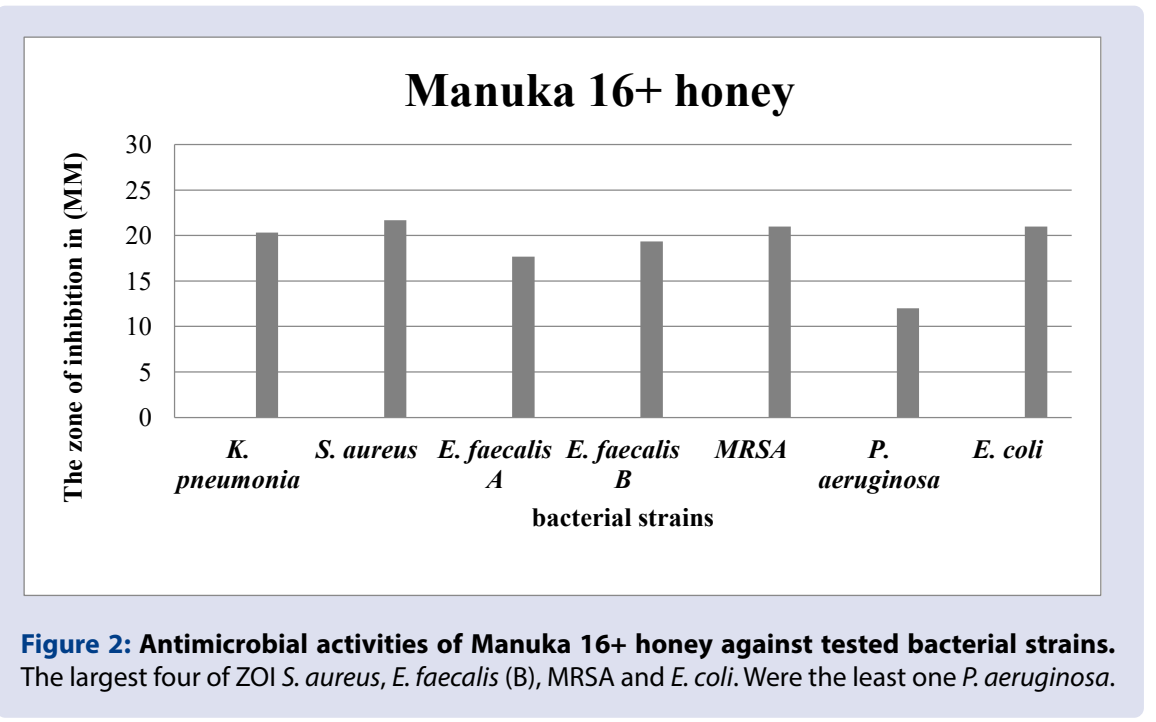

The largest four of ZOI S. aureus, E. faecalis (B), MRSA \& P. aeruginosa. Were the least one K. pneumonia.

\section{Zahoor honey}

The least effective honey type on the tested strains was ZH. MRSA and E. faecalis were found to be the most sensitive strains showing $15.6 \mathrm{~mm}$, while K. pneumonia only showing $12.6 \mathrm{~mm}$ ZOI (Figure 5).

BF honey was found to be the least effective type among the tested honeys. Only small ZOI was found in K. pneumonia $(12.3 \mathrm{~mm})$ and S. aureus $(12.3 \mathrm{~mm})$ (Figure 6).

\section{DISCUSSION}

All types of tested honey except BF honey displayed substantial antimicrobial activities against tested pathogenic bacterial strains. These primary findings may strengthen the idea that honeys can be used as potential alternative broad-spectrum strategy to treat bacterial infections. Many published studies determined the antimicrobial effects of various types of honeys, however, more extensive researches are necessary for conclusive declaration as substituting broad-spectrum antimicrobial drugs with different type's honey. 


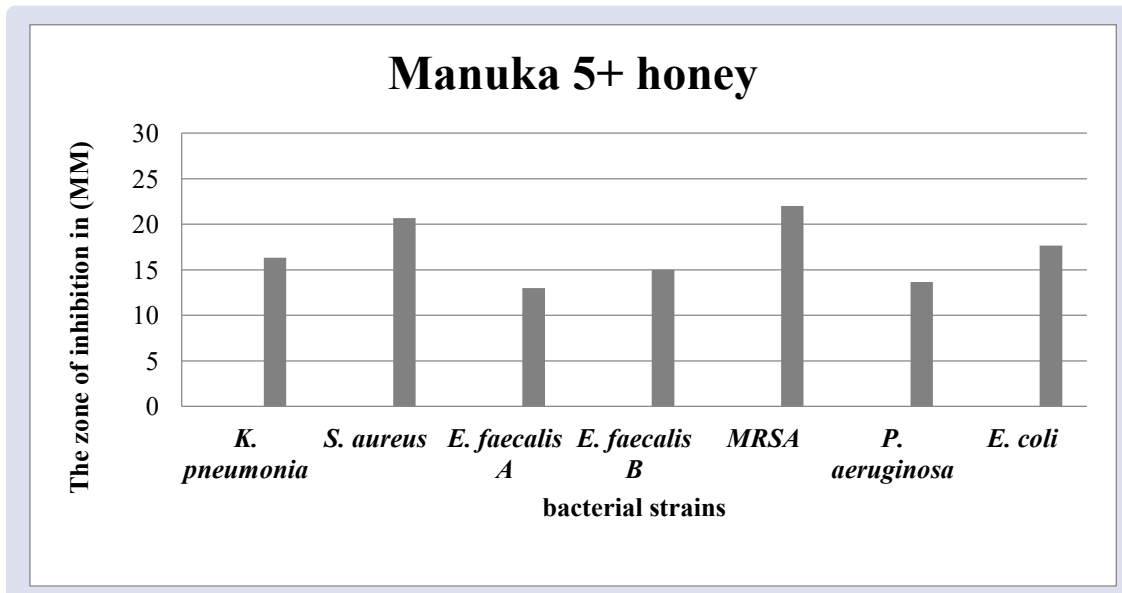

Figure 3: Antimicrobial activities of Manuka 5+ honey against tested bacterial strains. The largest two of ZOI S. aureus and MRSA. Were the least one P. aeruginosa.

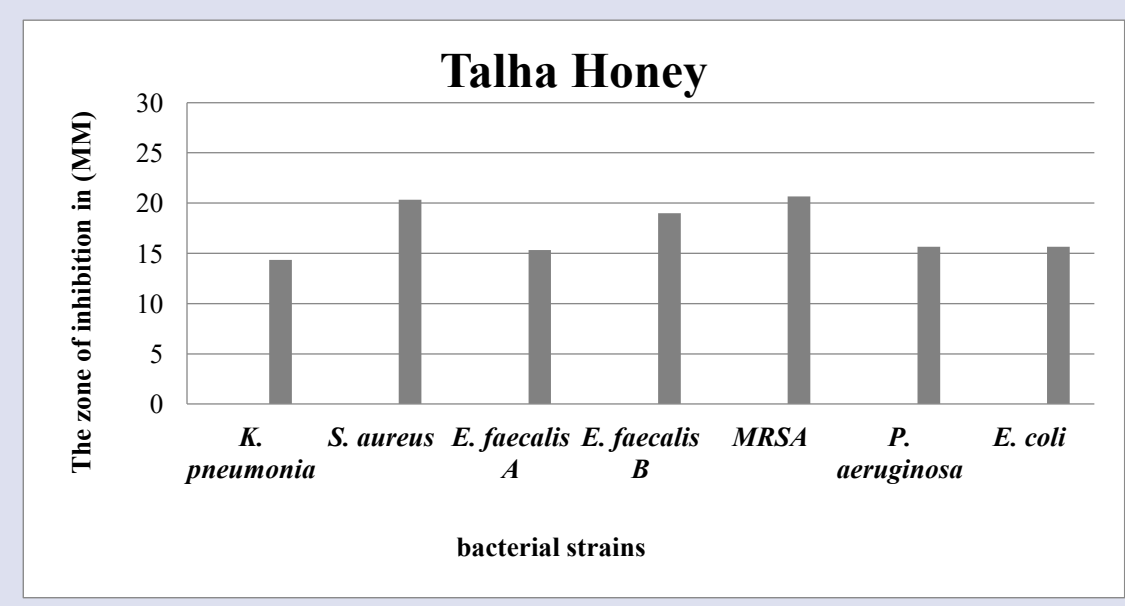

Figure 4: Antimicrobial activities of Talah honey against tested bacterial strains.

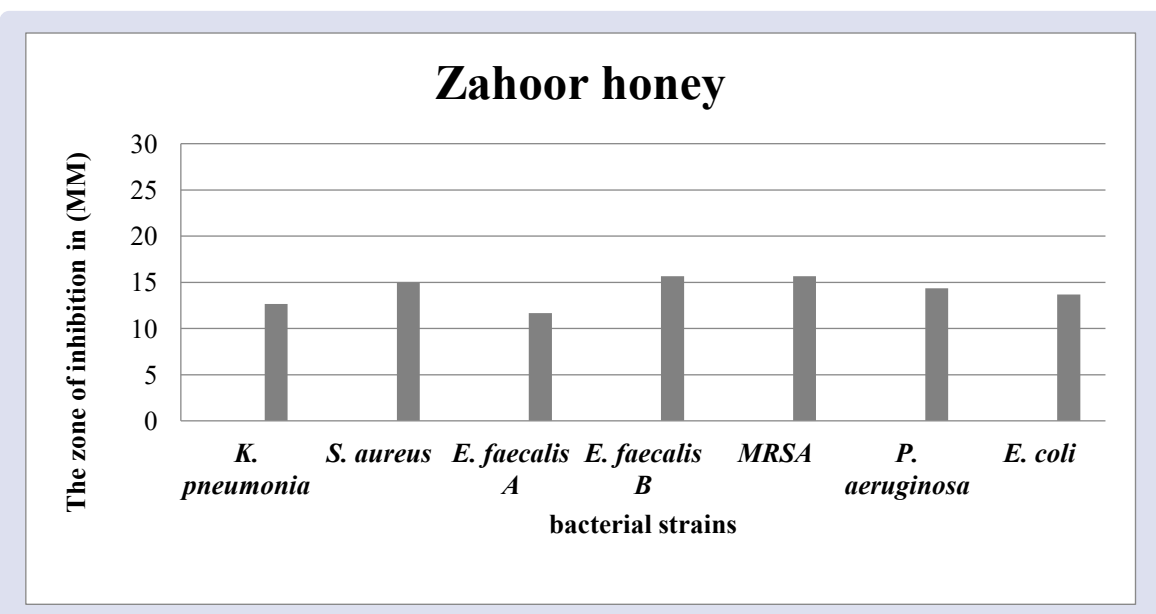

Figure 5: Antimicrobial activities of Zahoor honey against tested bacterial strains. The largest three of ZOI E. faecalis (B) \&MRSA. Were the least one K. pneumonia. 


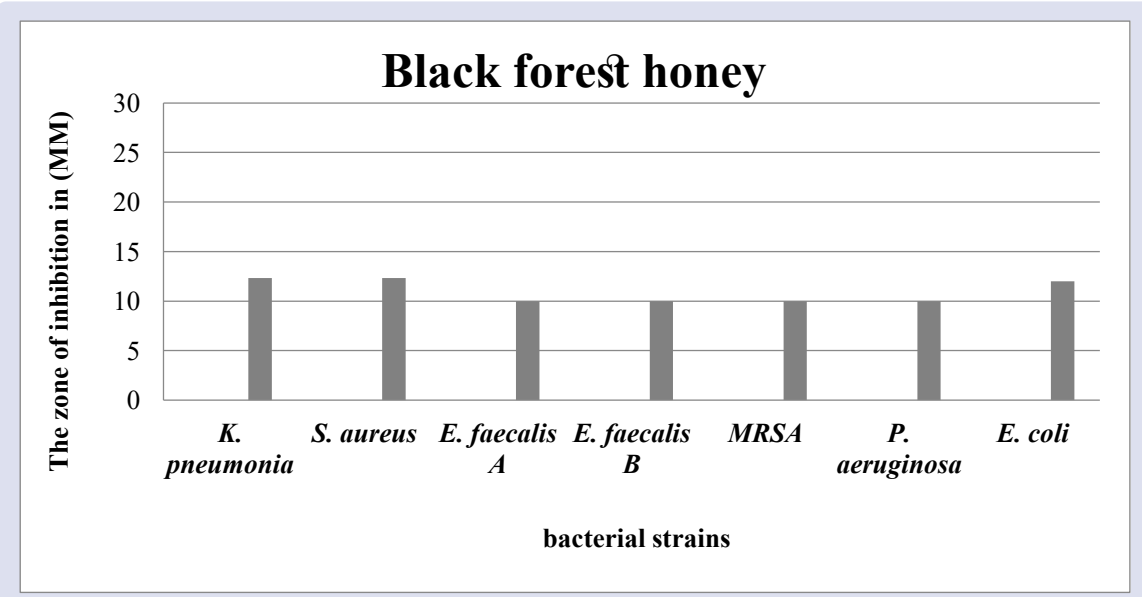

Figure 6: Antimicrobial activities of black forest honey against tested bacterial strains.

(A) $\mathrm{MA}+20$
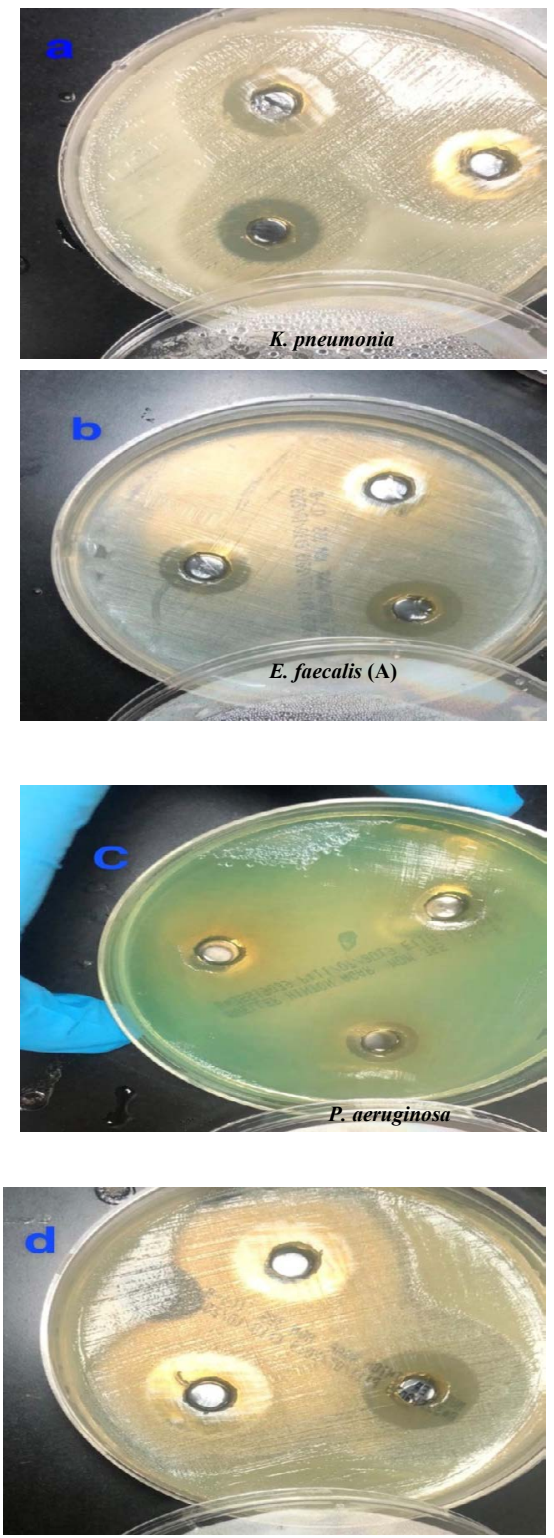

(B) $\mathrm{BF}$
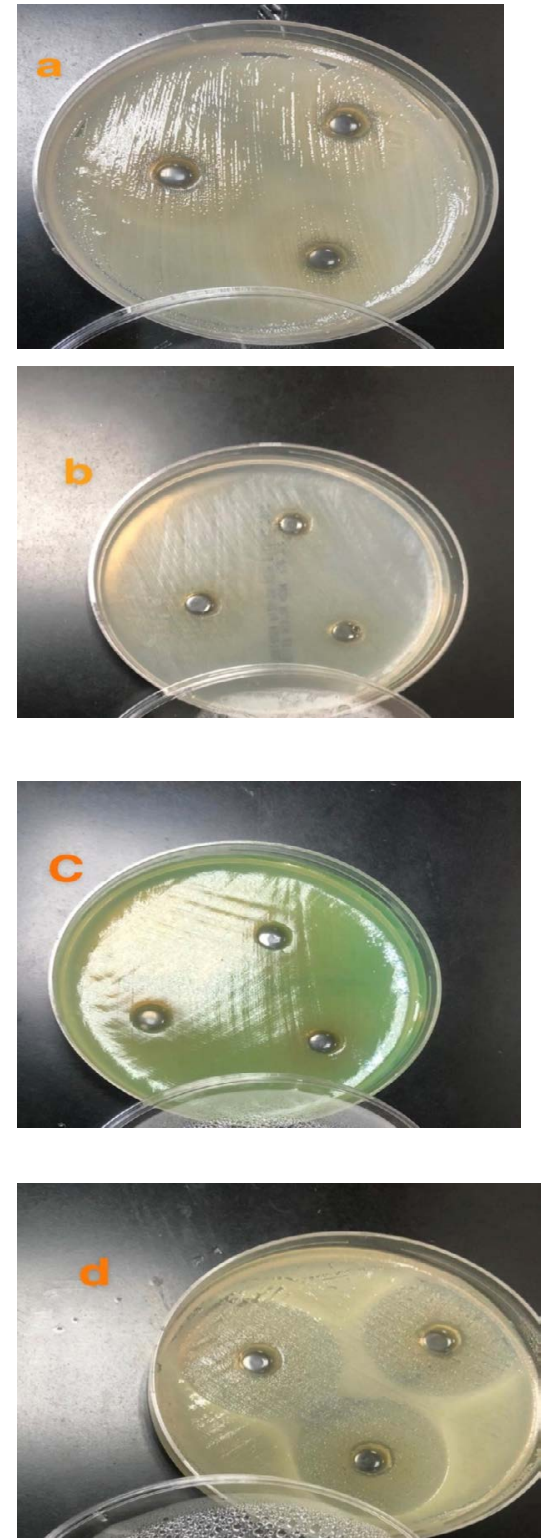


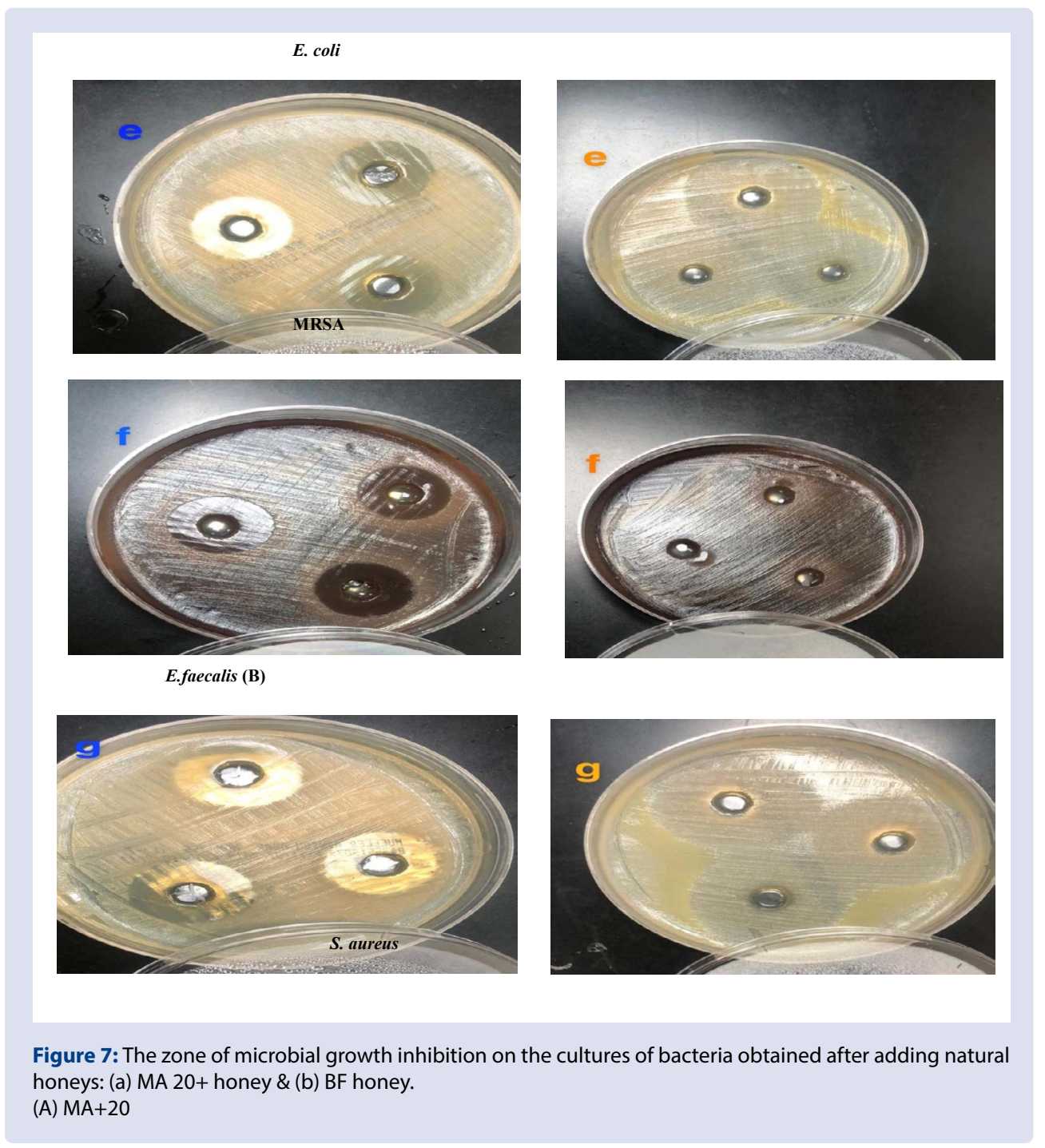

This study showed that all types of Manuka honey have strong antibacterial activities against all tested bacteria except $P$. aeruginosa. The most effected bacteria were S. aureus, MRSA, E. coli and E. faecalis. $\mathrm{MH}$ also showed smaller ZOI against K. pneumoniae and P. aeruginosa. This study is contradictory with other studies which showed that Manuka +20 , Manuka +16 and Manuka +10 were found to have strong antibacterial activities against both sensitive and resistant $P$. aeruginosa. Another study showed that Manuka honey of lower UMF grade demonstrated equal to significantly increased antimicrobial activity compared to higher UMF grade honey for all tested organism. ${ }^{10,11}$ Unlike to $\mathrm{MH}$, Talha and Zahoor honey types showed strong antibacterial activities against $P$. aeruginosa and some of other gram + and gram-bacteria. On the other hand, black forest honey showed the least inhibition (smallest ZOI). A very recent study demonstrated that Talha honey showed higher antimicrobial activities than Sidr honey. Both had strong antibacterial activities against pathogenic grampositive bacteria including Bacillus cereus and S. aureus, and gramnegative bacteria including $E$ coli and Salmonella enteritidis. ${ }^{12}$ This study also showed that Talha honey had great antibacterial activities against all tested bacterial strains including gram-positive and gram-negative strains. Very recent studies reported that TH has higher antibacterial activities than Somur, Meria and sider honeys. ${ }^{12}$ In contrast, this study illustrated another type of honey, $\mathrm{MH}$ exhibiting superior antibacterial activities against selected bacterial strains compared to TH. Black forest honey was previously found to have the highest antibacterial activities against $P$. aeruginosa ATCC 27853 and least against E. coli ATCC $25922 .{ }^{13}$ This study was also found that black forest honey has the least inhibition zone (smallest ZOI). All recorded diameters of inhibition zones in the present study were greater than $11 \mathrm{~mm}$ except BF. This result well aligns with the declaration of Agbagwa and FrankPeterside (2010) that "the diameter of inhibition zones less than $7 \mathrm{~mm}$ corresponds to resistant microorganisms and greater than $11 \mathrm{~mm}$ suggests that the microorganisms are sensitive to antimicrobial agent". ${ }^{14}$ Therefore, our findings are consistent in that all tested microbial strains were sensitive to tested honeys, and these honeys might be proposed as prospective antimicrobial agents to benefit human health.

\section{Physiochemical properties of honey}

The high viscosity of honey was previously found to provide the barrier in order to protect against bacterial infection into the host. ${ }^{15}$ Moreover, high sugar content of honey might affect the osmolarity which may lead to inhibit the microbial growth. ${ }^{16}$ Antibacterial activities of manuka honey (Leptospermum scoparium) against $S$. aureus, MRSA, and Pseudomonas spp. were demonstrated. These activities of honey were suggested to be depend on various factors that function either singularly or synergistically. ${ }^{17-19}$ The honey is well known to consists of hydrogen peroxide, phenolic compounds, lower $\mathrm{pH}$, osmotic pressure, and other phytochemical content. Furthermore, honey has the ability to generate hydrogen peroxide related antimicrobial activity. The production of hydrogen peroxide by transforming glucose substrate 
with glucose oxidase of honey depends on enzyme level and floral sources of honey. ${ }^{20} \mathrm{~A}$ study on Zahoor honey type (maltiflower honey) found that honey $\mathrm{PH}$ was ranged from 3.84 to 3.87 , Phenolic content ranged from $674.81 \mathrm{mg} \mathrm{GAE} / \mathrm{kg}$ to $674.81 \mathrm{mg} \mathrm{GAE} / \mathrm{kg}$ and flavonoid contents were in the range of $66.56 \mathrm{mg}$ quercetin $/ \mathrm{kg}$ to $79.75 \mathrm{mg}$ quercetin/kg. ${ }^{21}$ Therefore, all of these factors might have roles in the antimicrobial activities against tested pathogenic bacterial strains in the current study. The effect of honey on the development of bacterial resistance was determined and indicated that it might be very low duo to the variability in the composition among various types of honey which depends on some factors. These factors include types of nectar that the bees fed, the related weather conditions, storage time and conditions of preservation. ${ }^{22,23}$

\section{CONCLUSION}

All tested honey types except black forest, have exhibited antimicrobial activities on both gram-positive and gram-negative bacteria, especially S. aureus and MRSA. Manuka +20 and +16 were found to be more effective against all tested strain than other types, while black forest honey has no effectiveness. UMF was fond to be depend on MGO.

This study suggests that antimicrobial potential of honey types might be helpful in order to treat the pathogenic microorganisms threatening the public health and changing antibiotics into last-resort drugs. Further studies are required using different honey types on different bacterial strain in order to determine the exact composition of honey tested.

\section{REFERENCES}

1. White Jr JW. Honey. In Advances in food research. Academic Press. 1978;24;287-374.

2. El Sohaimy SA, Masry SHD, Shehata MG. Physicochemical characteristics of honey from different origins. Annals of Agricultural Sciences. 2015;60:279-87

3. Bucekova M, Jardekova L, Juricova V, Bugarova V, Di Marco G, Gismondi A, et al. Antibacterial activity of different blossom honeys: new findings. Molecules. 2019; 24;1573.

4. Vasić $\mathrm{V}$, Đurđić $\mathrm{S}$, Tosti T, Radoičić A, Lušić D, Milojković-Opsenica D, et al. Two aspects of honeydew honey authenticity: Application of advance analytical methods and chemometrics. Food Chem. 2020;305:125457.

5. Manivanan P, Rajagopalan SM, Subbarayalu M. Studies on authentication of true source of honey using pollen DNA barcoding. J Entomol Zool Studies. 2018;6:255-61.
6. Dustmann JH. Antibacterial effect of honey. Apiacta. 1979;14:7-11

7. Laallam H, Boughediri L, Bissati S, Menasria T, Mouzaoui MS, Hadjadj S, et al. Modeling the synergistic antibacterial effects of honey characteristics of different botanical origins from the Sahara desert of Algeria. Front Microbiol. 2015;6:1239

8. Mandal MD, Mandal S. Honey: its medicinal property and antibacterial activity. Asian Pacific J Trop Biomed. 2011;1:154

9. Nolan VC, Harrison J, Cox JA, Dissecting the Antimicrobial Composition of Honey. Antibiotics. 2019;8:251.

10. Al-Nahari AA, Almasaudi SB., El Sayed M, Barbour E, Al Jaouni SK, Harakeh S Antimicrobial activities of Saudi honey against Pseudomonas aeruginosa. Saudi J Biol Sci. 2015;22:521-5.

11. Girma A, Seo W, She RC. Antibacterial activity of varying UMF-graded Manuka honeys. PloS one, 2019;14(10).

12. Owayss AA, Elbanna K, Iqbal J, Abulreesh HH, Organji SR, Raweh HS, et al. In vitro antimicrobial activities of Saudi honeys originating from Ziziphus spina christi L. and Acacia gerrardii Benth. trees. Food Sci Nutr. 2020;8:390-401.

13. Nzeako BC, Hamdi J. Antimicrobial potential of honey on some microbial isolates. Sultan Qaboos Univ Med J [SQUMJ]. 2000;2:75-9.

14. Agbagwa OE, Frank-Peterside N. Effect of raw commercial honeys from Nigeria on selected pathogenic bacteria. African J Microbiol Res. 2010;4:1801-3.

15. Lusby PE, Coombes AL, Wilkinson JM. Bactericidal activity of different honeys against pathogenic bacteria. Arch Med Res. 2005;36:464-7.

16. Cooper RA, Molan PC, Harding KG. The sensitivity to honey of Gram positive cocci of clinical significance isolated from wounds. J Appl Microbiol. 2002;93:857-63.

17. Molan P, Betts JA. Clinical usage of honey as a wound dressing: an update. J Wound Care. 2004;13:353-6.

18. Moussa A, Noureddine D, Abdelmelek M, Saad A. Antibacterial activity of various honey types of Algeria against Pathogenic Gram-Negative Bacilli: Escherichia coli and Pseudomonas aeruginosa. Asian Pacific J Trop Dis. 2012;2:211-4.

19. Mulu A, Tessema B, Derbie F. In vitro assessment of the antimicrobial potential of honey on common human pathogens. The Ethiopian $\mathrm{J}$ Health Develop (EJHD). 2004;18(2).

20. Schneider M, Coyle S, Warnock M, Gow I, Fyfe L. Anti - microbial activity and composition of Manuka and Portobello Honey. Phytother Res. 2013;27:1162-8.

21. Jantakee K, Tragoolpua Y. Activities of different types of Thai honey on pathogenic bacteria causing skin diseases, tyrosinase enzyme and generating free radicals. Biol Res. 2015;48:4.

22. Sherlock O, Dolan A, Athman R, Power A, Gethin G, Cowman S, et al Comparison of the antimicrobial activity of Ulmo honey from Chile and Manuka honey against methicillin-resistant Staphylococcus aureus, Escherichia coli and Pseudomonas aeruginosa. BMC Complement Alternat Med. 2010;10:1-5.

23. Al-Waili NS, Boni NS. Natural honey lowers plasma prostaglandin concentrations in normal individuals. J Medicinal Food. 2003:6:129-33. 


\section{GRAPHICAL ABSTRACT}

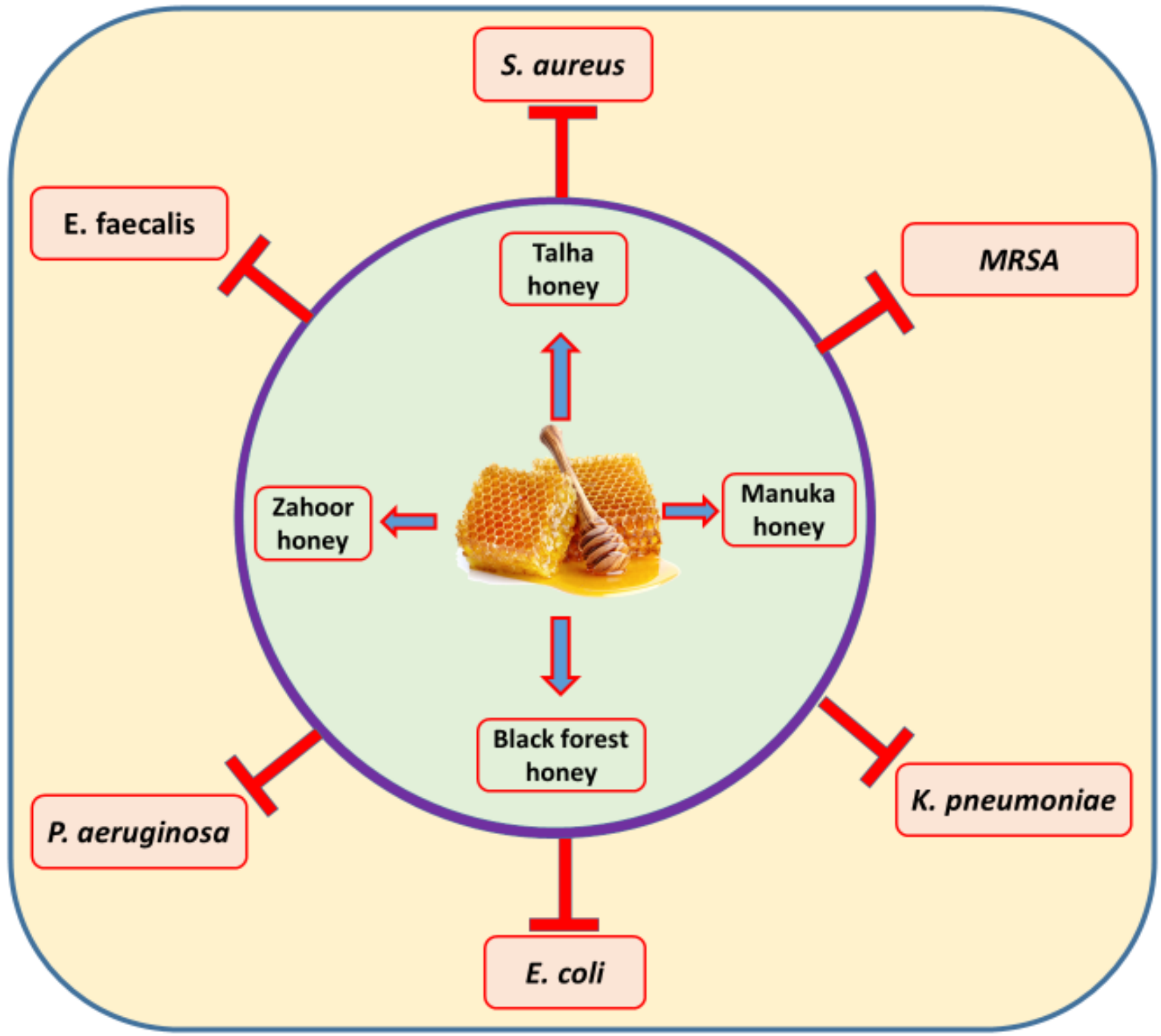

\section{ABOUT AUTHORS}

- Ahmad Almatroudi Is working as an Assistant Professor in the Department of Medical Laboratories, College of Applied Medical Sciences, Qassim University, Kingdom of Saudi Arabia. His research interests include measurement of the therapeutic potential of natural compounds in the management of diseases, Public health and Microbiology. Ahmad Almatroudi is currently chairman of Department of Medical Laboratories. He has published several meaningful research and review article, of international repute journal and has presented his papers in many national and international conferences.

- Dr. Amjad Ali Khan is currently working as Assistant Professor (since Oct. 2008) in Department of Basic Health Sciences, College of Applied Medical Science, Qassim University, Saudi Arabia. He got his Ph.D. in Biochemistry (2005) from AMU, India. In 2007 he joined as Postdoctoral Fellow in University of Minnesota, USA. Besides the academic activities at CAMS$\mathrm{QU}$, he is engaged in research work and is working as Co-Investigator on four different Interdisciplinary research projects. The major research areas are investigating the therapeutic potential of different medicinal plant extracts and purified compounds on diabetes and induced lung and liver cancers in animal models. 
- Arshad Husain Rahmani: Is working as an Assistant Professor in the Department of Medical Laboratories, College of Applied Medical Sciences, Qassim University, Kingdom of Saudi Arabia. His research interests include measurement of the therapeutic potential of natural compounds in the management of diseases and expression pattern of the genes linked to cancer development and progression. He has published more than 85 research and review article, of international repute journal. Besides this, he is an active reviewer of several ISI indexed journals.

- Faris Alrumaihi: Is as an Assistant Professor in the Department of Medical Laboratories and Vice Dean of College of Applied Medical Science for academic affairs, Qassim University, Kingdom of Saudi Arabia. His research interests include evaluation of the therapeutic potential of natural compounds in diseases management and expression pattern of genes linked to cancer development and progression. He has published several meaningful research papers in international repute journal and has presented his papers in many national and international conferences.

- Dr. Khaled S. Allemailem: is an Assistant Professor in the Department of Medical Laboratories, College of Applied Medical Science (CAMS), Qassim University, Saudi Arabia. He is also the Head of Basic Health Sciences in CAMS. He got his $\mathrm{PhD} \&$ Master degrees from RMIT University, Melbourne, Australia. His research interests include measurement of the therapeutic potential of natural compounds in the management of diseases, and Environmental \& Medical Microbiology. He has published several meaningful research papers in international repute journal and has presented his works in many national and international conferences.

- Dr. Lujain Aljaghwani: graduated as a bachelor student from the Department of Medicine and Surgery, College of Medicine , Qassim University, Saudi Arabia. She is now an Obstetric and gynecology resident doctor at the Maternity and Children Hospital in Buraydah, Qassim, Saudi Arabia. She has participated in many University activities including community services activities. She also obtained certificates in many courses after graduation. Lujain participated in the 11th Medical Research symposium" at Qassim University's Clinics on 5th December 2017 as a poster presentation.

- Mr. Mohammad Aljaghwani: graduated as a bachelor student from the Department of Medical Radiology, College of Applied Medical Sciences, Qassim University, Saudi Arabia. He is now an cardiovascular and catheter specialist at prince sultan center for cardiac medicine and surgery in Buraydah, Qassim, Saudi Arabia. He has participated in many University activities including community services activities. He also obtained certificates in many courses after graduation.

- Mr. Rejo Jacob Joseph is a lecturer in the College of Applied Medical Sciences, Qassim University, KSA, where he has been a faculty member since 2010. Rejo Completed his post-graduate in Medical Laboratory from Sri-Ramachandra University and his bachelor's degree at Rajiv Gandhi University of Health Sciences, India. Rejo is the practical instructor for Clinical Microbiology subjects on graduate students in the University. His research interest lies in the area of Clinical Microbiology, Antimicrobials, Histotechnology \& Clinical Pathology. He has collaborated actively with researchers at Qassim University.

- Miss Aseel Aljaghwani: recently graduated as a bachelor student from the Department of Medical Laboratories, College of Applied Medical Sciences, Qassim University, Saudi Arabia. She is now an internship student at the Maternity and Children Hospital in Buraydah, Qassim, Saudi Arabia. She has participated in many University activities including community services activities. She also obtained certificates in many courses after graduation. Aseel participated in MedLab Asia conference 2020 in Thailand as a poster presentation.

Cite this article: Aljaghwani A, Allemailem KS, Aljaghwani LF, Alrumaihi F, Joseph RJ, Khan AA, et al. Antimicrobial Effect of Different Types of Honey on Selected ATCC Bacterial Strains. Pharmacog J. 2021;13(1): 217-25 